\title{
A PECUÁRIA COMO ATIVIDADE PRIMAZ NA AMAZÔNIA: UMA DISCUSSÃO ACERCA DOS SEUS ASPECTOS AMBIENTAIS, DAS POPULAÇÕES HUMANAS ENVOLVIDAS E DO PAPEL DAS INSTITUIÇÕES NA DINÂMICA DESTA ATIVIDADE
}

Livestock activity as primate in the Amazon: a discussion of its environmental, human populations involved and the role of institutions in the dynamics of this activity

\author{
Cláudia Pinheiro Nascimento ${ }^{1}$ \\ Mauricio Silva ${ }^{2}$ \\ Manoela Barros Pedreira Ferreira ${ }^{3}$
}

Resumo: Tomando como base para análise a leitura dos atores individuais e coletivos e o papel das instituições na dinâmica da atividade pecuária, este artigo tem como objetivo demonstrar os impactos sociais e humanos e as razões para manutenção da pecuária como principal atividade econômica desenvolvida na Amazônia, mesmo considerando-se os impactos socioambientais discutidos pela comunidade científica.

Palavras-chave: Pecuária, Amazônia, Impactos ambientais, Populações Envolvidas, Instituições.

Abstract: Based on analysis to the reading of individual and collective actors and the role of institutions in the dynamics of the livestock activity, this article aims to demonstrate the social and human impacts and the reasons for cattle raising maintenance as main economic activity developed in the Amazon, even considering the social and environmental impacts discussed by the scientific community.

Keywords: Cattle breeding, Amazon, Environmental Impact, Population Involved, Institutions.

JEL: 013

\section{INTRODUÇÃO}

A pecuária é hoje a principal atividade econômica da Amazônia, seus impactos sociais e ambientais são globais e têm sido discutidos em diferentes esferas científicas. Mas se essa atividade é tão prejudicial porque ainda continua como predominante?

Este texto tem como objetivo demonstrar quais os impactos ambientais e humanos da atividade e as razões para sua manutenção na Amazônia.

\footnotetext{
1'Geógrafa. Doutoranda do Núcleo de Altos Estudos Amazônicos da Universidade Federal do Pará. nascimento.cp@gmail.com

${ }^{2}$ Geógrafo. Mestre em Engenharia Civil pela Universidade Federal de Santa Catarina. Especialista em Geoprocessamento na Agência Nacional de Águas. mauricio.silva@ana.gov.br

${ }^{3}$ Geógrafa. Mestranda em Geografia do Programa de Pós-Graduação da Universidade Federal do Paraná. manuh.geo@hotmail.com
} 
Para isso, o texto foi dividido em quatro partes principais: a primeira parte tem como objetivo demonstrar a partir do mapeamento do uso e cobertura do projeto TerraClass realizado pelo INPE (Instituto Nacional de Pesquisas Espaciais), a predominância das áreas de pastagens e sua associação com o desenvolvimento da pecuária. A segunda parte busca apresentar como se deu o estabelecimento da pecuária na região, assim como, as vantagens ambientais, econômicas, políticas, sociais e históricas que contribuíram para o estabelecimento da sua primazia na região. A terceira parte traça um paralelo entre a pecuária e os principais problemas ambientais da Amazônia, partindo da discussão dos diferentes impactos, dos atores individuais e coletivos envolvidos e da repercussão global dos problemas ambientais da região. E por fim, na quarta parte, busca-se relacionar a pecuária com as populações humanas envolvidas na tentativa de verificar os impulsos migratórios presentes no processo assim como os processos adaptativos presentes.

Para a construção do texto, foram utilizados o método de revisão bibliográfica e o acesso aos dados secundários concernentes ao assunto abordado, na tentativa de responder à questão estabelecida na relação entre a pecuária, seus aspectos ambientais, humanos e as instituições envolvidas no processo.

\section{2. Dados sobre Mapeamento e o Uso da Terra na Amazônia - Terraclass}

O mapeamento do INPE, sobre o uso e cobertura da terra nas áreas desflorestadas da Amazônia, confirma a primazia da atividade da pecuária na Amazônia.

Para a Amazônia Legal brasileira o projeto TerraClass ${ }^{4}$ mapeou as classes de cobertura e uso da terra e seus respectivos percentuais como demonstrado a seguir: a classe pasto limpo, representando 46,7\% o maior percentual do total mapeado (área ocupada de $335.714,94 \mathrm{~km}^{2}$ ), seguida das áreas de vegetação secundária que representam $21 \%$ do total mapeado(área ocupada de $150.815,31 \mathrm{~km}^{2}$ ), das áreas de pasto sujo que perfazem $8,7 \%$ do total mapeado (área ocupada de $62.823,75 \mathrm{~km}^{2}$ ) e das áreas de regeneração com pasto correspondem a 6,7\% do total mapeado (área ocupada de 48.027,37 $\left.\mathrm{km}^{2}\right)$.

Conforme a tabela 01 e a figura 01, é possível observar que as áreas de agricultura anual perfazem 4,9\% do total mapeado (área ocupada de 34.927,24 $\mathrm{km}^{2}$ ), a classe mosaico de ocupações, 3,4\% (área ocupada de $24.416,57 \mathrm{~km}^{2}$ ) e as áreas urbanas, 0,5\% (área ocupada de 3.818,14 km²).

\footnotetext{
${ }^{4}$ Entre os anos de 2009 e 2011 o INPE e a Embrapa (Empresa Brasileira de Pesquisa Agropecuária) desenvolveram um projeto buscando estabelecer um novo ponto de partida para a leitura do que viria a cobrir as áreas desflorestadas na Amazônia através do projeto TerraClass. Este projeto buscou realizar o mapeamento em escala equivalente ao PRODES (Projeto de Estimativa do Desflorestamento) do uso e da cobertura da terra para as áreas que, segundo o PRODES Digital, sofreram o corte raso da vegetação florestal existente. A área acumulada designada como desflorestada em vinte anos (1988-2008) cerca de 720 mil quilômetros quadrados, corresponde às áreas mapeadas pelo TerraClass. O projeto apresentou onze classes de uso e cobertura da terra que evidenciam as principais causas históricas do desmatamento como: pasto limpo, pasto sujo, pasto com solo exposto e regeneração com pasto, agricultura anual, mosaico de ocupações, área urbana e mineração.
} 
Tabela 01 - Distribuição das áreas correspondentes a cada classe temática mapeada

\begin{tabular}{l|c|c|c}
\hline \multicolumn{1}{c|}{ Classe } & $\begin{array}{c}\text { Área (km ao } \\
\text { quadrado) }\end{array}$ & $\begin{array}{c}\text { Frequência } \\
\text { Absoluta }\end{array}$ & $\begin{array}{c}\text { Frequência } \\
\text { Acumulada }\end{array}$ \\
\hline $\begin{array}{l}\text { Pasto Limpo } \\
\text { Vegetação }\end{array}$ & $335.714,94$ & $46,7 \%$ & $46,7 \%$ \\
$\begin{array}{l}\text { Secundária } \\
\text { Pasto Sujo }\end{array}$ & $150.815,31$ & $21,0 \%$ & $67,6 \%$ \\
$\begin{array}{l}\text { Regeneração } \\
\text { com Pasto }\end{array}$ & $62.823,75$ & $8,7 \%$ & $76,4 \%$ \\
Área Não & $48.027,37$ & $6,7 \%$ & $83,1 \%$ \\
$\begin{array}{l}\text { Observada } \\
\text { Agricultura }\end{array}$ & $45.406,27$ & $6,3 \%$ & $89,4 \%$ \\
$\begin{array}{l}\text { Anual } \\
\text { Mosaico de }\end{array}$ & $34.927,24$ & $4,9 \%$ & $94,2 \%$ \\
$\begin{array}{l}\text { Ocupações } \\
\text { Área Urbana }\end{array}$ & $24.416,57$ & $3,4 \%$ & $97,6 \%$ \\
$\begin{array}{l}\text { Mineração } \\
\text { Pasto com Solo }\end{array}$ & $3.818,14$ & $0,5 \%$ & $98,2 \%$ \\
$\begin{array}{l}\text { Exposto } \\
\text { Outros }\end{array}$ & 730,68 & $0,1 \%$ & $98.3 \%$ \\
$\begin{array}{l}\text { Desflorestament } \\
\text { os 2008 }\end{array}$ & 494,19 & $0,1 \%$ & $98.3 \%$ \\
TOTAL & $11.458,64$ & $1,6 \%$ & $98,4 \%$ \\
\hline
\end{tabular}

Fonte: Projeto TerraClass, 2011. Disponível em:

http://www.inpe.br/cra/projetos_pesquisas/sumario_executivo_terraclass_2008.pdf, acesso em 03 de setembro de 2012.

Reunidas todas as categorias, as áreas de pasto correspondem a $62,1 \%$ do total desflorestado, o que ocorreu primordialmente devido à atividade pecuária, confirmando sua primazia na região analisada. Estudos desenvolvidos por Riveroet al., (2009) demonstram esta atividade como o principal uso do solo na Amazônia.

A pecuária bovina é o uso do solo mais importante em todos Estados da Amazônia. É uma atividade, que, em geral, tem apresentado crescimento em todos os Estados. Esses fatos tornam a criação de gado a atividade econômica de maior impacto em toda a região (Riveroet al.,2009, p.63)

A pecuária causa à região, danos socioambientais que somente podem ser explicados a partir do seu processo de formação sócio espacial, das dinâmicas econômicas e da lógica dos atores e instituições envolvidas. 
Figura 01 - Gráfico das classes mapeadas pelo projeto TerraClass

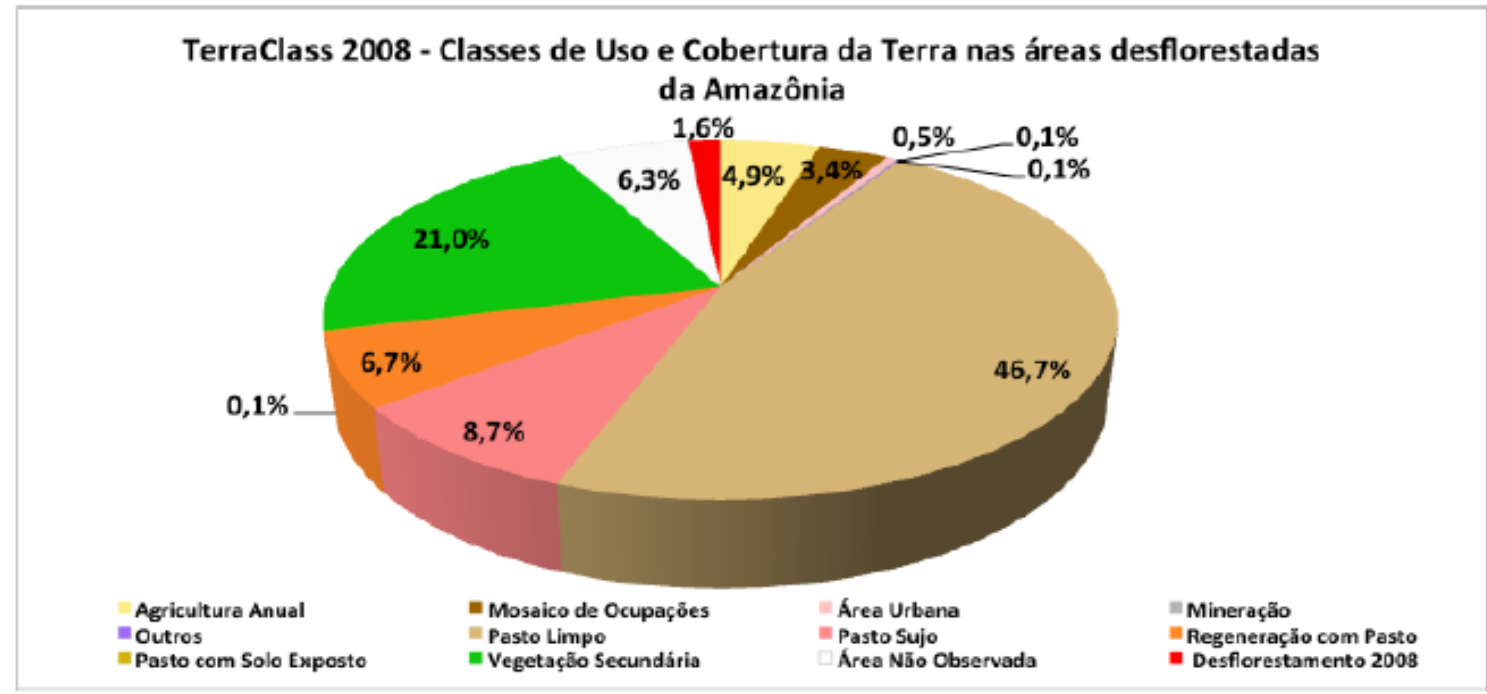

Fonte:Projeto TerraClass, 2011. Disponível em:

http://www.inpe.br/cra/projetos_pesquisas/sumario_executivo_terraclass_2008.pdf, acesso em 03 de setembro de 2012.

\section{A PECUÁRIA COMO ATIVIDADE PREDOMINANTE NA AMAZÔNIA}

Diante de tantas atividades que poderiam ser desenvolvidas na Amazônia, uma indagação pode ser feita: porque a pecuária foi a atividade que mais se desenvolveu na região?

Segundo Faminow, (apudMARGULIS, 2003, p. 15), o desenvolvimento da atividade na região, especialmente com a criação de gado bovino, ocorre por apresentar diversas vantagens adicionais em relação a outras formas de usos do solo, muitas das quais foram de fato corroboradas pela pesquisa de campo de Margulis (2003):

- Ainda que conhecida, é uma óbvia forma de garantir a posse da terra, o que é uma prioridade absoluta na fronteira como já visto;

- Em relação à agricultura, principalmente às culturas temporárias, o risco da atividade é baixíssimo em termos de mercados, de comercialização, de preços dos produtos (a despeito da leve tendência de queda, o preço da carne tem crescido em relação ao das principais culturas agrícolas), das condições climáticas e de pragas;

- Também em relação à agricultura, demanda menores investimentos iniciais e apresenta retornos positivos num período muito menor de tempo;

- É uma forma de capital líquido, facilmente transacionável, apresenta transporte relativamente facilitado e tem baixíssima demanda por mão de obra;

- É ótima para ludibriar todo tipo de fiscalização (ao contrário da terra cultivada); 
- $\quad$ No caso dos pequenos produtores, há benefícios indiretos, como a obtenção de outros produtos animais, a tração, a adubação, além da venda da madeira, que vale também para os grandes produtores;

- No caso dos grandes proprietários, confere status político e cultural de estar entre os grandes fazendeiros ou latifundiários.

Segundo Margulis (2003, p.34), a evolução do rebanho bovino na Amazônia está associada à rentabilidade da pecuária em partes da Amazônia, conforme os dados da tabela 02 . "O crescimento do rebanho bovino na Amazônia respondeu pela maior parte do crescimento do rebanho bovino do país, sugerindo uma expansão da fronteira pecuária em direção ao norte", sendo, Mato Grosso, Pará e Rondônia os estados de maior rebanho bovino da região Norte.

Tabela 02 - Evolução do rebanho bovino (1990-2009), em mil animais

\begin{tabular}{|c|c|c|c|c|c|c|c|c|}
\hline & 1990 & 1995 & 1998 & 2000 & 2003 & 2005 & 2006 & 2009 \\
\hline BR & 147.102 & 161.227 & 163.154 & 169.875 & 195.551 .576 & 207.156 .696 & 205.886 .244 & 205.260 .154 \\
\hline MT & 9.041 & 14.153 & 16.751 & 18.924 & 24.613 .718 & 26.651 .500 & 26.064 .332 & 27.357 .089 \\
\hline PA & 6.182 & 8.058 & 8.337 & 10.271 & 13.376 .606 & 18.063 .669 & 17.501 .678 & 16.856 .561 \\
\hline Ro & 1.718 & 3.928 & 5.104 & 5.664 & 9.392 .354 & 11.349 .452 & 11.484 .162 & 11.532 .891 \\
\hline
\end{tabular}

Fonte: Margulis, (2003, p.34) e dados da Pesquisa Pecuária Municipal (IBGE, 2010). Dados organizados pelos autores.

Diferentes fatores são apontados para o crescimento da pecuária na Amazônia. Uma delas é a lucratividade da atividade na região associada aos baixos preços da terra, pois, em boa parte da Amazônia, não existem usos alternativos à pecuária e a maior produtividade das pastagens está nos principais centros pecuaristas, apresentando áreas voltadas para a agricultura mecanizada, devido ao aumento do custo dos grãos e dos ganhos de produtividade da agricultura (ARIMA, et al., 2005).

Outra vantagem apontada é a produtividade das pastagens nas principais regiões produtoras (sul do Pará, Mato Grosso e Rondônia), conforme tabela 02, que segundo Arimaet al., (2005, p. 11) foram cerca de $10 \%$ mais produtivas que o restante do Brasil. Esse nível elevado na produção está associado a algumas condições climáticas favoráveis como a maior distribuição de chuvas nessa área, com um valor acima de $1600 \mathrm{~mm} /$ ano e inferior a $2200 \mathrm{~mm} / \mathrm{ano}$ e a ausência de geadas na região (ARIMA, et al., 2005, p.11).

Os aumentos da produtividade associados ao baixo custo das pastagens justificam a compensação dos menores preços recebidos pelo gado na Amazônia, pois o retorno recebido pelos investimentos é maior, mesmo que o valor recebido na região seja de 10 a $19 \%$ mais baixo do que o recebido pelos produtores do Centro-Sul (ARIMA, et al., 2005, p.11).

Todos estes fatores levantados estão associados de forma direta com as causas recentes que contribuíram para o estabelecimento da pecuária como a principal atividade da região, fatores históricos também precisam ser considerados pela sua relevância para a questão. 


\subsection{Aspectos Históricos do Processo de Ocupação da Amazônia e da Constituição da Pecuária como Atividade Principal}

A alteração territorial presenciada hoje na Amazônia resulta de mudanças que ocorreram na sociedade e na economia nas últimas décadas. $O$ ordenamento territorial da Amazônia reflete a visão e a ação de diferentes níveis de atores que agem de forma conjunta ou individualmente, interferindo diretamente no processo de formação sócio espacial e nas atividades desenvolvidas na região.

Castro (2007) analisa o ordenamento territorial da Amazônia a partir da racionalidade dos atores individuais e coletivos envolvidos e suas motivações na definição das estratégias sócio espacias, sendo assim, a perda da cobertura vegetal, seja em função da exploração madeireira, agropecuária ou mineração é reflexo da diversidade de lógicas e racionalidades que determinam as práticas sociais. Na perspectiva de Fearnside (2005), as políticas de incentivos fiscais e subsídios governamentais, foram os grandes indutores do desflorestamento da Amazônia, principalmente entre os anos de 1970 e 1980, assim como as políticas econômicas implantadas no Brasil.

Segundo Alves (2001), foi a partir da década de 1970 que o processo de ocupação da Amazônia acelerou-se e milhões de hectares de florestas foram derrubadas para a criação de pastos, projetos de colonização e reforma agrária.

Segundo lanni (1979, p.36), durante os anos de 1964 a 1969, a problemática amazônica era tratada pelos governos federal, estaduais, territoriais e municipais dentro da perspectiva de vazio demográfico, vazio econômico, escassez de recursos de capital, dispersão de recursos humanos e econômicos, insuficiência de meios de transportes e comunicações, predomínio de atividades econômicas e extrativistas, identificação entre borracha e Amazônia, populações e culturas indígenas desconhecidas, terras virgens ou pouco cultivadas, fartas e talvez férteis ou ricas, inclusive em minerais, cobiça internacional e geopolítica.

Este período foi marcado por um modelo desenvolvimentista e de integração, pautado por políticas de ocupação de cunho geopolítico, que foram concretizadas por meio da implantação de grandes projetos de colonização e de mineração. A política de incentivos fiscais voltada principalmente, para os grandes projetos agropecuários também se fez presente, viabilizando a transformação de áreas florestais em pastagens (FEARNSIDE, 1985; MAHAR, 1989; BECKER, 1998).

As políticas implantadas estavam associadas também a outras necessidades que se configuravam dentro do quadro nacional, como, por exemplo, amenizar problemas sociais que surgiam em outras regiões, como conflitos fundiários, ausência de titularidade, pressão e necessidade de uma reforma agrária brasileira (MAHAR, 1989; IANNI, 1979; BECKER, 1998).

Essa perspectiva conveniente aos interesses das oligarquias locais e regionais, juntamente com os órgãos criados pelo Governo Federal, foi responsável pela formulação de diagnóstico e adoção de medidas para 0 desenvolvimento capitalista na Amazônia. 
As medidas de desenvolvimento regional na Amazônia, segundo Kohlhepp (2002, p.38) podem ser divididas em duas categorias: a ação estatal que inclui o desenvolvimento de infraestrutura, principalmente rodoviário, projetos de colonização e redução de impostos para atrair investidores privados, a ação privada baseada em investimentos em todos os setores econômicos, mediante incentivos fiscais; e a redução de taxas tributárias para serem empregados principalmente na criação de gado, indústria e projetos de mineração.

Dentro dessa perspectiva o desmatamento foi considerado pelo INCRA (Instituto Nacional de Colonização e Reforma Agrária) como a atividade principal de benfeitoria, sendo na grande maioria das vezes condição primordial para a liberação de financiamentos, de incentivos fiscais e para a redução de taxas tributárias.

Todas essas medidas desenvolvimentistas de ação privada ou estatal contribuíram para o fortalecimento do desmatamento na região e para a construção de instituições, dentro do contexto do conjunto de regras e normas (NORTH, 1993) sejam elas formais ou informais, como agentes de perpetuação dessas ações na região.

Juntamente com esse processo teremos o estabelecimento de planos e órgãos governamentais que se estabelecem na região e que vão contribuir para a continuidade das ações de desmatamento e da perpetuação da pecuária.

Órgãos governamentais de financiamento e gerenciamento foram criados na década de 1970 tais como o INCRA, a SUDAM (Superintendência para o Desenvolvimento da Amazônia) assim como, programas de integração, incluindo-se aqui o PIN I e o PIN II (Programa de Integração Nacional) e os pólos de desenvolvimento como o POLOAMAZÔNIA (Programas de Pólos de Desenvolvimento Agropecuários e Agrominerais na Amazônia).

Os planos aplicados nesse momento ocorreram sem planejamento e tiveram assim muito pouco sentido, compreenderam um conjunto de elementos de ação prática e seguiram uma construção sem passar por todos os níveis responsáveis pela administração, sendo assim, segundo Prebisch (1964, p. 75) não conseguiram alcançar o seu objetivo principal, que era promover 0 desenvolvimento a partir da integração nacional.

As ações do governo na região na década de 1980 resultaram em redução de despesas públicas, sendo os recursos concentrados em poucas e selecionadas áreas com o intuito de fomentar as exportações na região. 0 Programa Grande Carajás e o Projeto Calha Norte representam essa nova realidade do país e exprimem a forma como o governo remodelou suas ações sobre a Amazônia (PRATES, 2008).

Além dos projetos mencionados para a década de 1980, é implantado ainda, em 1982, em Rondônia e no norte do Mato Grosso, o POLONOROESTE (Programa Integrado de Desenvolvimento do Noroeste do Brasil), que teve como intuito absorver contingentes populacionais de mão de obra, por meio de melhoria de infraestrutura, aumento de produtividade agrícola e da geração de renda das atividades agropecuárias através de financiamentos concedidos pelo Banco Mundial (SANTOS, 2007). 
Todas as ações realizadas, seja na forma de planos de desenvolvimento ou na criação de órgãos governamentais, estão impregnadas pela condição ineficaz, mal preparada, incompetente e frequentemente corrompida do estado, apontada por Myrdal (1961) como condição característica dos estados dos países subdesenvolvidos, contribuindo assim para a perpetuação das mesmas práticas mesmo que em um contexto histórico diferente e sob a ação de atores diferenciados.

\subsection{As Políticas e Incentivos para o Fortalecimento da Atividade Pecuária na Amazônia Atualmente}

Associada a questão da disponibilidade de terra, e aos fatores ambientais da região que favorecem a produção de gado pode-se também apresentar outros elementos como contribuintes para o fortalecimento da atividade, estes estão vinculados, sobretudo à constituição das instituições na região que vão demandar a aplicação de leis e incentivos através de programas desenvolvidos nacional ou internacionalmente.

Essa situação não é algo novo na região, desde o início do seu processo de ocupação, a Amazônia seguiu um padrão de ocupação que atendeu aos interesses de atores individuais e coletivos e suas motivações na definição das estratégias sócio espaciais (CASTRO, 2007).

A partir do ano de 1985, dois novos processos se estabelecem na região amazônica, um representando as verticalidades, de cunho exógeno, 0 esgotamento do nacional desenvolvimentismo e da intervenção do Estado na economia e no Território, e outro representando as horizontalidades, o modelo endógeno, com a criação do Conselho Nacional dos Seringueiros, simbolizando a resistência das populações à expropriação da terra (BECKER, 1998).

A questão do desflorestamento atinge na década de 1980 uma maior repercussão, quando o INPE passa a fazer o monitoramento das taxas anuais de corte raso na Amazônia, para incrementos anuais superiores a 6,25 hectares, através do projeto PRODES.

Associado ao mapeamento realizado pelo INPE foram elaboradas políticas ambientais brasileiras e instituídos órgãos governamentais que garantissem a aplicação das mesmas. Em 1980, no governo do então Presidente José Sarney, deu-se início Nossa Natureza", e no ano de 1988, com a criação do IBAMA (Instituto ao projeto de desenvolvimento das políticas ambientais com a criação do "Programa Brasileiro do Meio Ambiente e Recursos Naturais Renováveis) (PRATES, 2008).

O cenário que envolve a região nesse momento, é o de desenvolvimento de projetos ambientais com a colaboração internacional, tais como o PPG-7 (Programa Piloto para a Proteção das Florestas Tropicais) em cooperação com a União Europeia e com o Banco Mundial, o LBA (Large Scale Biosphere Atmosphere Experiment in the Amazon), cujo grande parceiro é a NASA (National Aeronautics and Space Administration), o PROBEM (Programa Brasileiro de Ecologia Molecular da Biodiversidade da Amazônia), cujos parceiros são laboratórios, além de empresas para o desenvolvimento de 
biotecnologias e os projetos SIPAM (Sistema de Proteção da Amazônia) e SIVAM (Sistema de Vigilância da Amazônia).

Novamente a partir do ano de 1996 o modelo exógeno de crescimento da região é retomado com a implantação do Programa Brasil em Ação, no qual o Governo Federal, através do Ministério do Planejamento e do Orçamento, retoma o planejamento econômico e territorial no país (BECKER, 2001, p.149).

A efetivação do planejamento ocorreu com o PAB (Programa Avança Brasil) e teve sua execução no período de 2000 a 2003, cuja complementação ocorreu até o ano de 2007.

As motivações básicas do PAB foram: a) estimular e assegurar as exportações nacionais, ampliando-as para o hemisfério Norte; b) estreitar as relações com os países sul americanos, visando a consolidação do MERCOSUL em toda a América do Sul (BECKER, 2001).

A componente central do PAB centrava-se na estratégia territorial e visava à intensificação da fluidez do território, pautada em uma logística complexa e em áreas prioritárias. Incluía não apenas redes de circulação e comunicação, como de energia e seus pontos de suporte, mas também sistemas multimodais de transporte e comunicações, visando o aumento de sua velocidade e eficiência.

Os principais instrumentos do PAB são: o PPA (Plano Plurianual de Investimento (PPA), que expressa a estratégia federal e define as áreas prioritárias para alocação dos recursos orçamentários da União e os ENIDS (Eixos de Integração e Desenvolvimento).

Todas essas ações foram substituídas por uma nova ação de desenvolvimento no Brasil, através do PAC (Programa de Aceleração do Crescimento), implantado no ano de 2007, já em sua segunda edição no ano de 2012, com a criação do PAC (2) com previsão de investimento até o ano de 2020.

Essas políticas de desenvolvimento ocorrem de forma conjunta com a construção de políticas de cunho ambiental, que visam solucionar os problemas que passam a surgir como preocupação nacional e internacional.

Foi, porém, segundo os dados do PRODES nos anos de 1994 e 2004, que as taxas de desmatamento alcançaram seus maiores índices. A alternativa encontrada pelo governo foi a instituição do PPCDAM(Plano de Ação para a Prevenção e Controle do Desmatamento na Amazônia), elaborado no ano de 2004.

A construção do PPCDAM ocorreu através da instituição de subgrupos criados no âmbito do Grupo Permanente de Trabalho Interministerial para a Redução dos Índices de Desmatamento da Amazônia Legal. Esta alternativa encontrada pelo governo pode ser associada à teoria da Ação Coletiva de Olson (1999), que tenta explicar o comportamento de indivíduos racionais que se associam para a obtenção de algum benefício coletivo, onde a composição de grupos menores tem a capacidade de maior resolução dos problemas.

Neste caso, o que impulsionou este grupo menor a trabalhar em prol da constituição de benefícios coletivos foram os "incentivos sociais" relacionados ao prestígio social que teriam, e que segundo Olson (1999) podem ser analisados na forma de "incentivos monetários", ou seja, estes incentivos pessoais se 
traduziriam em monetários na forma da ocupação de cargos comissionados, posição de gerência e cargos de chefia.

Juntamente com o PPCDAM temos o PAS (Plano Amazônia Sustentável) que compreende um conjunto de objetivas e diretrizes estratégicas, elaborados a partir de um diagnóstico atualizado da Amazônia contemporânea e de seus desafios, e visa orientar para um novo modelo de desenvolvimento, no qual as soluções econômicas sejam ambientalmente sustentáveis. Suas ações compreendem um pacto entre os governos estaduais e federais agrupados em quatro eixos temáticos; 1) Ordenamento Territorial e Gestão Ambiental; 2) Produção Sustentável com Inovação e Competitividade; 3) Infraestrutura para o Desenvolvimento e 4) Inclusão Social e Cidadania.

Além das práticas antagônicas presentes nas políticas governamentais que focavam em ações contraditórias como plano de desenvolvimento de infraestrutura e planos de contenção de desmatamento, as políticas e incentivos para o desenvolvimento da pecuária na região também se apresentaram fora dos contextos das políticas nacionais, o que demonstra a força dos atores locais na constituição destas políticas.

Nessa medida, apesar dos inúmeros projetos governamentais, a iniciativa de transformação da floresta em pasto se perpetuou até as medidas mais austeras de comando e controle iniciadas com o PPCDAM, estando a Amazônia sujeita à expansão da pecuária extensiva sobre as áreas desflorestadas até meados de 2005.

A expansão expressiva da pecuária na Amazônia nos dias atuais, segundo Arimaet al., (2005, p.11) contou com vantagens adicionais como acesso relativamente fácil às terras públicas e a baixa aplicação da lei florestal, que permite acúmulo de capital por meio da exploração ilegal da madeira onde parte é investida na pecuária.

Ainda dentro desse contexto, podemos destacar os "fundos constitucionais destinados à Amazônia Legal que emprestam dinheiro a taxas de juros de $6 \%$ a 10,75\% ao ano (bem abaixo da praticada no mercado), permitem descontos de $15 \%$ a $25 \%$ para produtores adimplentes e possibilitam que associações contratem crédito em nome de pequenos produtores que não possuem título definitivo das terras" (ARIMA, et al., 2005, p. 11).

A formação sócia espacial da Amazônia ao longo do seu processo histórico nos permite afirmar que, apesar de todo o esforço da aplicação de políticas e planos de desenvolvimento na busca da tentativa de vencer o subdesenvolvimento da região, esta condição não foi alcançada. Muitos dos fatores ineficientes nessa tentativa estão atrelados aos círculos viciosos de efeito cumulativo que se implantaram na região, responsáveis pelo fracasso das ações mesmo constituindo-se a partir de novos atores, pois não possibilitaram mudanças estruturais profundas.

Muitas das políticas e ações implantadas com o intuito de vencer os processos degradatórios da região não conseguem se estabelecer visto a força do papel das instituições na região, seja na forma de conjunto de regras e normas ou na constituição de órgãos e políticas, como agentes de perpetuação dos processos, assim como, o papel das ideologias, seja no comportamento de 
governantes, de grupos de interesse ou de agentes do judiciário, para o entendimento da perpetuação do arcabouço teórico da sociedade amazônica.

\section{A PECUÁRIA E OS PROBLEMAS AMBIENTAIS NA AMAZÔNIA}

O principal problema ambiental da Amazônia é o desmatamento de suas florestas. Este processo tem impactos ambientais severos, inclusive perda de biodiversidade, exposição do solo à erosão, perda das funções da floresta na ciclagem da água e armazenamento do carbono (FEARNSIDE, 2003).

Segundo Castro (2005), para o entendimento da dinâmica do desmatamento, é importante associar a interpretação dos princípios da racionalidade econômica à análise das estratégias de caráter político dos agentes econômicos de espaços diferenciados da Amazônia.

Dentro dessa perspectiva, é necessário levar em consideração quatro pontos fundamentais. Em primeiro lugar, não existe apenas uma causa do desflorestamento, trata-se de múltiplas causas que dizem respeito à diferença da racionalidade de atores e de suas estratégias. Em segundo, essa alteração espacial está organicamente relacionada à estrutura social do Brasil, desigual em renda e oportunidades. Em terceiro, há uma relação entre essas causas e a modalidade de inserção da Amazônia e do País na economia mundial globalizada. Finalmente, o último ponto diz respeito aos arranjos políticos e à disponibilidade de recursos naturais no território (CASTRO, 2005, p. 09).

Embora exista uma discussão sobre os vários atores que contribuíram para o desflorestamento, a pecuária é apontada como a atividade por excelência responsável pela maior parte do dele (MARGULIS, 2003; ALENCAR et al., 2004; FEARNSIDE, 2005; CASTRO, 2005; COSTA, 2005).

O papel da pecuária no desflorestamento se associa, sobretudo, às crescentes extensões de terra por ela ocupadas, à padronização do uso da terra e à concentração fundiária por ela proporcionada, como estratégia de formação de estoques para o mercado futuro de terras (CASTRO, 2007).

A lucratividade é um dos fatores de peso na expansão da pecuária na Amazônia, em virtude da renda proporcionada pelas atividades que entram como fatores de complementaridade, como o caso das madeireiras, dos garimpos, do comércio, da pequena produção familiar, dos serviços e outras formas de extrativismo (FEARNSIDE, 2005; CASTRO, 2007).

A expansão da pecuária não está associada somente à disponibilidade de capital para investimento, associa-se também, à expansão dos mercados internos e externos, à demanda por carne bovina no exterior e aos incentivos fiscais (ALENCAR et al., 2004).

A dinâmica da pecuária, nesse caso, passa a seguir uma lógica independentemente da imposta pelo mercado nacional: a possibilidade da supressão do espaço pelo tempo, em função da implantação do meio técnico cientifico internacional (SANTOS, 2006), contribui para que o mercado internacional e suas tendências atuem também nos mecanismos de organização da pecuária na região, e consequentemente pela organização do espaço amazônico. 
Margulis (2003) aponta a eliminação das barreiras sanitárias, com a erradicação da febre aftosa, o melhoramento das raças bovinas e das forragens e a evolução da engenharia genética, como fatores que fazem da pecuária um investimento de baixo custo de produção, encarado como um meio de poupança e uma fonte segura de recursos monetários para seus produtores.

A maior parte da expansão da pecuária ocorre em grandes propriedades, embora essa prática esteja sendo também disseminada em propriedades de pequenos agricultores que apresentam objetivos diferentes. Para os pequenos agricultores, o investimento na produção bovina, ocorre como forma de diversificar sua fonte de renda, com a adoção de sistemas de pecuária mista, com gado de corte e leite (WALKER etal., 2000).

Os grandes pecuaristas focam seu interesse na produção especializada e empresarial, com desenvolvido aparato tecnológico que o permite alcançar maior lucratividade.

Alencar etal., (2004), atribui a expansão do rebanho bovino à rentabilidade da pecuária e à dinâmica expansiva dos mercados de carne, porém, aponta a complementaridade de outros fatores, como a especulação da terra e os créditos subsidiados, elementos necessários para o entendimento do processo de "pecuarização" da região.

\subsection{Pecuária, Desmatamento e Mudanças Climáticas}

As florestas tropicais nas quais se inclui a Amazônia, são vulneráveis às mudanças climáticas que ameaçam a sua biodiversidade, bem como, os povos tradicionais e outros que dependem do seu sustento para sobreviver (FEARNSIDE, 2008, p.06). Segundo Fearnside (2008, p.06), "emissões de gases do efeito estufa provocadas pela mortalidade da floresta devido à mudança de clima fazem parte de uma relação de retroalimentação positiva em potencial que conduz a cada vez mais aquecimento e mais mortalidade".

Segundo CERRI et al. a maior parte das emissões de GEE (gases do efeito estufa) no ano de 1994 foi advinda da mudança de uso da terra no Brasil. Do total de GEE, 74\% são emissões de gás carbônico sendo $3 \backslash 4$ oriundas da substituição das florestas por pastagens e 114 do setor energético (1/4). Isso demonstra o impacto que o desmatamento tem nas emissões de GEE oriundas do Brasil.

Na Amazônia a substituição da floresta por meio do desmatamento tem demonstrado uma queda significativa nas taxas, porém, os efeitos dos desmatamentos passados refletem no atual uso das terras com a predominância de coberturas de pastagens ligadas às atividades de pecuária. A permanência de uma cobertura da terra diferente da anterior implica em impactos diretos na flora, com o advento de espécies exóticas a esses ambientes alterados que, muitas vezes, não possuem consumidores ou predadores, transformando esse ambiente antes diverso em uma verdadeira monocultura de espécies herbáceas.

A substituição da floresta pela pastagem altera também o balanço energético diário e por consequência as trocas de calor ao longo das estações do ano. Segundo Cohen, 2007(apud Souza, 2010) esta dinâmica ao longo do tempo, deve ser considerada nos modelos de circulação geral e de mesoescala, 
pois, trata-se de alterações importantes do balanço geral de energia. A alteração do dossel e a remoção da cobertura, antes florestal por uma predominantemente herbácea, podem causar significativas alterações do balanço hídrico, principalmente no que se refere à evapotranspiração.

A Floresta Amazônica tem um papel importante na ciclagem da água na região: segundo Fearnside (2003), metade da chuva é atribuída à água reciclada através das árvores. Portanto, a transformação das áreas de floresta em pastagem tem efeitos importantes na ciclagem da água e na precipitação.

"Considerando que a evapotranspiração é proporcional à área foliar, a quantidade de água reciclada pela floresta é muito maior que a quantidade reciclada pela pastagem, especialmente na estação seca quando a pastagem fica seca enquanto a floresta permanece verde. Isto é agravado pelo maior escoamento sob pastagem... Solo sob pastagens é altamente compactado, inibindo assim a infiltração de água da chuva. A chuva que cai em solo compactado escoa rapidamente pela superfície, ficando assim indisponível para liberação posterior para a atmosfera pela transpiração. Pastagens e capoeiras (florestas secundárias) têm sistemas radiculares mais rasos do que os de floresta primária, impedindo a retirada de água durante estiagens" (Cochrane et al., 1999; Nepstad et al., 1994, 1999b in Fearnside, 2003, p.21).

Segundo Santos de Souza et al., (2003), a conversão da Floresta Amazônica em pastagem, reduzirá as chuvas nas regiões Centro-Oeste, Centro Sul e Sul do país.

Fearnside (2003) aponta inúmeras alterações na Amazônia relacionadas às mudanças climáticas, dentre elas, as alterações da cobertura da terra que por consequência trazem redução da biodiversidade, invasão de espécies exóticas, fragmentação dos habitats e alteração nos estoques de carbono. A fragmentação do habitat sem especial, leva ao contato de espécies de fauna de áreas abertas (campos) ou semiabertas (arbustivas) com espécies de área fechada (florestas). Esse contato, propiciado pela abertura de novas áreas para pasto, geram concorrências por alimento entre as diferentes espécies de fauna levando à redução drástica das populações nativas.

Outro aspecto a ser considerado está nos animais do topo da cadeia alimentar, que passam a ficar mais expostos e acabam por predar o próprio rebanho bovino como é o caso da onça pintada, constantemente caçada e morta por realizar abates ao rebanho, principalmente nas propriedades mais próximas da fronteira de avanço do desmatamento; e de espécies de morcegos carnívoros que atacam o rebanho e em função da transmissão de doenças, são caçados e exterminados em nome da saúde do rebanho invasor de seu habitat.

A exploração madeireira também deve ser considerada como um problema ambiental dentro do contexto desmatamento/pecuária, segundo 
Fearnside (2003, p.16) "a exploração madeireira facilita o desmatamento porque o dinheiro proveniente da venda da madeira pode ser investido em desmatamento para pastagens".

O maior impacto da exploração madeireira é a liberação de carbono para a atmosfera que exceda em muito o carbono nos troncos removidos. Segundo Fearnside (2003, p.16), "isto ocorre porque muito da biomassa das árvores colhidas é deixada para trás na forma de galhos, tocos e raízes, e porque os danos colaterais para árvores não colhidas resultam na morte e decomposição de muitas outras árvores. Apesar do "sequestro" (captura e estocagem) temporário de algum carbono em produtos madeireiros, o impacto líquido da exploração madeireira é uma liberação de carbono; a liberação é particularmente grande se é dado valor ao tempo nos cálculos dos benefícios climáticos".

A transformação do uso da terra tem íntima relação com o uso do fogo. As queimadas são utilizadas como forma de abrir novas áreas, corrigir a pobreza de nutriente e alta acidez dos solos da Amazônia e também, repetidas vezes após a abertura, como forma barata de manter a área livre para a produção pecuária. Essa atividade ainda tem grande impacto por eliminar em boa parte 0 banco de sementes presentes nos solos, impedindo assim, sua regeneração florestal espontânea e levando os solos a um esgotamento produtivo, e em alguns casos a perdas muito significativas de solo e arenização.

Os problemas ambientais causados pelo ciclo da pecuária, que inclui retirada da madeira nobre para venda, desmatamento e o fogo, não tem abrangência somente local: seu alcance é global, sendo assim, as medidas para sua conservação requerem ações que extrapolem as fronteiras amazônicas.

SegundoHurrel e Kingsbury (1991) a humanidade está diante de uma série de problemas que agora são globais e que só podem ser geridos de forma eficaz com a cooperação de todos, ou pelo menos com a participação de uma porcentagem muito elevada dos estados do mundo.

Existe, porém, um desafio a ser vencido nesse caso, que é a articulação de um grande grupo que consiga obter cooperação entre seus participantes no intuito de obter regras e leis que tenham abrangência internacional e que consigam adentrar os estados sem interferir na autonomia dos mesmos (HURREL; KINGSBURY, 1991).

Parte dessa articulação tem sido realizada por instituições como o Banco Mundial, oFMI (Fundo Monetário Internacional), oGATT (General Agreement on Tariffs and Trade), peloo G7, porém essas são as principais instituições que governam o funcionamento da economia mundial(HURREL e KINGSBURY, 1991). Dentro deste contexto é necessário o rompimento da busca dos interesses individuais e o estabelecimento de uma instituição que represente os interesses coletivos e que seja capaz de elaborar leis que resolvam a questão dos problemas ambientais globais.

\subsection{A Pecuária e as Populações Humanas Envolvidas}

A relação entre as transformações da pecuária e as populações humanas envolvidas, será analisada levando-se em consideração a Ecologia Cultural de Julio Stewart, que estuda os aspectos adaptativos, por meio dos quais as 
sociedades são afetadas pelos ajustes básicos realizados pelos seres humanos para utilização do meio.

Levando em consideração a Ecologia Cultural de Julio Stewart, que estuda os aspectos adaptativos por meio dos quais as sociedades são afetadas pelos ajustes básicos e que através deles o homem utiliza o meio, analisaremos a relação entre as transformações da pecuária e as populações humanas envolvidas.

Dentro da perspectiva da ecologia cultural, a noção de adaptação é primordial e pode ser definida como diferentes estratégias que o homem criou para explorar os recursos naturais e para enfrentar as limitações ecológicas que pesam sobre a reprodução dos recursos naturais e dos próprios grupos humanos (DIEGUES, 2001, p. 45).

A apropriação de áreas comunitárias na Amazônia é proveniente da expansão da grande propriedade rural, voltada à atividade da agropecuária, das políticas públicas (criação de áreas naturais protegidas) e dos grandes projetos mineradores.

Populações ribeirinhas, povos tradicionais, povos indígenas e populações extrativistas foram os mais afetados por esses processos. Em todos os projetos de assentamento não se levou em conta o modo de vida das populações tradicionais, como o ocorrido com as populações negras antigas do rio Trombetas, no Pará (DIEGUES, 2001).

Remanescentes de antigos quilombos, com direitos garantidos pela Constituição, foram expulsos de seu território ou tiveram suas atividades tradicionais duramente restringidas. Em suas terras foram implantadas a Mineradora Alcoa, a hidrelétrica de Trombetas e duas áreas protegidas: a Estação Ecológica de Trombetas (1979) e a Floresta Nacional de SaracáTaquara (1989) (ACEVEDO; CASTRO, 1993).

Todos estes processos ocorrem em função do fundamento do processo de ocupação da região, que segundo Castro (2010) está associado ao Mito do El Dourado, onde nas relações do imaginário, é construída arelação do homem com a natureza, e, necessariamente, com os modelos utilizados para sua transformação em mercadoria, fato que permeia as ações e consegue mobilizar sonhos de conquista megalomaníacos, desde a implantação dos primeiros núcleos missionários no séc. XVII até as ações dos dias atuais.

Para Bertha Becker (1998, p.11) a ocupação da Amazônia deve ser refletida a partirdo conceito de fronteira, visto não como sinônimo de terras devolutas, cuja apropriação econômica é franqueada a pioneiros ou camponeses, mas sim como um espaço social e político ainda não totalmente estruturado, potencialmente gerador de realidades novas.

Independente do contexto aceito para a construção da fronteira amazônica, analisada do ponto de vista da expansão, do ponto de vista do modo de produção capitalista, ou do ponto de vista das relações que se estabelecem a dinâmica econômica vigente na região baseada na exploração direta de recursos da floresta, promoveu processos migratórios. Primeiramente com destino aos projetos de colonização e em um segundo momento a contribuição da migração interna para a concentração de núcleos urbanos que tiveram papel 
importante na fixação de populações migrantes na Amazônia, fora das áreas dos assentamentos.

As levas de migrantes que se estabeleceram na Amazônia podem ser caracterizadas como migrantes ambientais (RENAUD et al., 2007), pois mesmo nos diferentes períodos do estabelecimento dos processos migratórios, vinham para a região buscando fugir de problemas ambientais que ocorriam nos seus locais de origem.

As levas de migrantes nordestinos que vieram tanto no primeiro quanto no segundo ciclo da borracha, foram atraídas para a região com o intuito de livrarse dos períodos de seca nordestina em 1866 e 1969. Os migrantes que vieram do Centro Sul, a partir da década de 1970, buscavam fugir de problemas tais como; falta de terra para o cultivo e de recursos para exploração na região.

Muitos desses povoados formados pelos migrantes estiveram ligados às iniciativas de mineradoras, madeireiras ou até mesmo de obras estatais, todos envolvidos na ideia de bem público de Olson (1999). Esse processo migratório permitiu a fixação de povos de várias outras regiões do Brasil, incluindo áreas urbanas e rurais, principalmente, do Nordeste, de Minas Gerais, do Paraná e de Santa Catarina ligadas às cidades de apoio às atividades agropecuárias. A herança trazida por esses migrantes aproximou os aspectos dessas cidades às de suas regiões de origem, bem como, se integraram aos modos de vida das populações tradicionais formando assim uma grande miscigenação de culturas.

O processo migratório desse momento vai impor à região uma nova realidade, pelo embate cultural que se estabelece, quando culturas, hábitos e costumes diferenciados passam a ter de conviver em um mesmo espaço.

Novas relações são criadas, quando lógicas atuais se confrontam com realidades existentes.

Esse embate de culturas, hábitos e costumes se estabelece na região, desde as décadas de 1930 e de 1940 quando se inicia a implantação dos primeiros núcleos agropecuários na Amazônia. A partir daí surgem instituições (no sentido de hábitos e costumes de North) que perpetuam até os dias atuais, e que mesmo com a alteração dos atores individuais e coletivos que agem na região, acabam por se perpetuar na forma de órgãos governamentais e das leis que são estabelecidas (NORTH, 1993).

A perpetuação da tradição da pecuária na região enquadra-se nesse contexto, pois diante de todo debate ambiental acerca dos seus malefícios para a região e de todas as ações coercivas aplicadas à atividade, seja na forma da obrigatoriedade do CAR (Cadastro Ambiental Rural) ou do LAR (Licenciamento Ambiental Rural), a atividade permanece como prioritária na região.

A dinâmica da pecuária sobre a população da Amazônia vai marcar o segundo momento de adaptação da população. Primeiramente foram as atividades mineradoras, os projetos de colonização e os projetos agropecuários os grandes responsáveis por ela. Atualmente a pecuária é a atividade que dinamiza esse processo, sendo sua atuação não somente sobre os povos da floresta, indígenas ou ribeirinhos com a expansão de suas áreas nas unidades de conservação e áreas indígenas, mas também, com a expulsão dos antigos migrantes dos projetos de colonização. 
A grande migração desses pequenos produtores rurais ocorre, sobretudo, para as cidades, visto a dificuldade encontrada para desenvolverem suas atividades, seja na obtenção de financiamentos que são escassos ou na concorrência com os grandes fazendeiros. Outro aspecto a ser considerado é a pressão dos fazendeiros na compra de suas terras e a atração do imaginário da vida urbana sobre a população rural.

As cidades passam então a concentrar as populações expropriadas pela atividade da pecuária, vivenciando um grande aumento populacional e consequentemente diversos problemas socioambientais.

Sendo assim, a expansão da pecuária acarreta problemas não somente à população que se desenvolve ao seu entorno, comotem alcances muito maiores que precisam ser considerados no desenvolvimento de políticas para seu retrocesso.

\section{CONSIDERAÇÕES FINAIS}

A predominância da atividade pecuária na Amazônia associa-se às mudanças que ocorreram na economia e na sociedade nas últimas décadas. A ação de diferentes atores, individuais e coletivos, tem influência direta na forma como se organizou o espaço e nas atividades desenvolvidas na região.

A década de 1970 foi decisiva nesse processo, pois, se caracterizou pela ocupação e desflorestamento de milhões de hectares para a criação de pastos, projetos de colonização e reforma agrária, caracterizando-se por instituir um conjunto de normas e costumes, formais e informais, responsáveis pela perpetuação dessas ações na região.

A continuidade da atividade pecuária na Amazônia ao atendimento dos interesses políticos dos grandes proprietários de terra. Pela demanda de custos menores (desde o preço da terra aos custos gerais de produção e produtividade), se comparada à agricultura, essa atividade tem demonstrado outra serventia: a de garantir de forma facilitada a posse da terra aos proprietários desse tipo de empreendimento.

Ainda que os danos ambientais associados à pecuária sejam reconhecidos e comprovados cientificamente, as medidas tomadas como tentativa de contençãoda expansão da pecuária não têm sido suficientes. Énecessário que haja a cooperação de instituições, geridas de forma que se consiga obter a participação das diferentes instituições envolvidas, no intuito de obter regras e leis que tenham abrangência internacional, e que consigam adentrar os estados sem interferir em sua autonomia.

Socialmente, a pecuária tem atingido principalmente as populações ribeirinhas, os povos indígenas, as populações tradicionais e as populações extrativistas, em virtude da aplicação de políticas públicas voltadas à expansão da grande propriedade rural e dos grandes projetos mineradores. Atualmente 0 destino dessa população tem sido os grandes bolsões de pobreza das cidades do entorno desses projetos.

Mesmo diante de ações coercivas aplicadas à atividade de pecuária, como a obrigatoriedade do CAR (Cadastro Ambiental Rural) e do LAR 
(Licenciamento Ambiental Rural) isso em nada alterou o desenvolvimento e a expansão dessa atividade.

Observa-se assim, que a manutenção da atividade pecuária na Amazônia está arraigada não apenas às questões financeiras ou ambientais, mas ao próprio modelo de desenvolvimento adotado para a região, o qual historicamente esteve pautado na concentração de terras e na degradação ambiental, até hoje beneficiadas pela falta de fiscalização por parte dos órgãos públicos. Fato esse que tem contribuído fortemente à estruturação de uma pecuária nociva, onde tanto os impactos sociais quanto ambientais têm sido negativos. A atual importância que a atividade pecuária tem na região amazônica, pode considerarse também, como resultante da constituição do espaço agrário brasileiro, em que, historicamente os latifundiários têm sido beneficiados, inclusive legalmente, através de intervenções e incentivos governamentais.

\section{REFERÊNCIAS BIBLIOGRÁFICAS}

ACEVEDO, R.; CASTRO, E. Negros do Trombetas: guardiães de matos e rios. Pará: UFPA/NAEA, 1993.

ALENCAR, A.; NEPSTAD, D.C.; MCGRATH, D.; MOUTINHO, P.; PACHECO, P.; DIAZ M del C.V. \& SOARES-FILHO, B. 2004. Desmatamento na Amazônia: Indo Além da Emergência Crônica. Instituto de Pesquisa Ambiental da Amazônia (IPAM), Belém, Pará, Brasil. 87 p.

ALVES, D. S. O processo de desmatamento na Amazônia. Parcerias Estratégias, Brasília: v.12, n. 1, p. 259-275, set. 2001.

ARIMA, E.; BARRETO, P.; MARKY, B. Pecuária na Amazônia: tendências e implicações para a conservação ambiental. Belém: Instituto do homem e meio ambiente da Amazônia, 2005. 76p.

BECKER, B. K. AMAZÔNIA. São Paulo: Editora Ática, 1998. p.112.

Revisão das políticas de ocupação da Amazônia: é possível identificar modelos para projetar cenários? Parcerias Estratégicas, Brasília, v.12, n.1, p.135-159, set. 2001.

BOLLE, W. CASTRO, E. VEJMELKA, M. (Org.). Amazônia: Região Universal e Teatro Mundial. São Paulo: Editora Globo, 2010. 1ํ Ed.

CASTRO, E. Dinâmica socioeconômica e desmatamento na Amazônia. Novos cadernos do NAEA, Belém, v.08, n.2, p.05-40, 2005.

Políticas de ordenamento territorial, desmatamento e dinâmicas de fronteira. Novos cadernos do NAEA, Belém, v.10, n.2, p. 105126, 2007.

CERRI, C. C. et al., Brazilian greenhouse gas emissions: the importance of agriculture and livestock, Sci. Agric. (Piracicaba, Braz.), v.66, n. 6, p.831-843, 2009.

COSTA, F. A. Questão Agrária e macropolíticas para a Amazônia. Estudos Avançados, São Paulo, v. 19, n. 53, p. 131-156, 2005. 
DIEGUES, A. C. S. O mito moderno da natureza intocada. São Paulo: Hucitec, 2001, 3르. ed.

FEARNSIDE, P. M. Environmental change an deforestation in the Brasilian Amazon. In: HEMMING, J. (ed.) Change in the Amazon Basin: man's impact on forest and rivers, v. 01. Manchester/UK, p. 70-89, 1985.

INPA, 2003. $134 \mathrm{p}$.

A floresta amazônica nas mudanças globais. Manaus:

índices e conseqüências. Megadiversidade, Belo Horizonte, v.01, n.01, p. 113123, 2005.

Mudanças climáticas globais e a floresta amazônica. pp. 131-150. In: Biologia e Mudanças Climáticas Globais no Brasil. Marcos S. Buckeridge (ed.), RiMa Editora, São Paulo, Brasil. 295 p, 2008.

HURRELL, A.; KINGSBURY B. The international Politics of the Environment. Oxford: Clarendon Press, 1991.

IANNI, O. Colonização e Contrarreforma Agrária na Amazônia. Petrópolis: Editora Vozes, 1979, 137p.

KOHLHEPP, G. Conflitos de Interesse no ordenamento territorial da Amazônia brasileira. Estudos Avançados, São Paulo, v. 16, n. 45, p. 37-61, 2002.

OLSON, M. A lógica da ação coletiva: os benefícios públicos e uma teoria dos grupos sociais. São Paulo: Editora da Universidade de São Paulo, 1999.

PRATES, R. C. O desmatamento desigual na Amazônia brasileira: sua evolução, suas causas e consequências sobre o bem estar. 2008. Tese (doutorado) - Doutorado em Ciências/Economia Aplicada - Universidade de São Paulo, Piracicaba - SP.

Renaud, F.; Bogardi, J. J.; Dun, O.; Warner, K. "Control, Adapt or Flee: How to face environmental migration? InterSections, n. 5, 2007.

RIVERO, S.; ALMEIDA, O.; ÁVILA, W. Pecuária e Desmatamento: uma análise das principais causas diretas do desmatamento na Amazônia. Revista Nova Economia, Belo Horizonte, v. 19, n. 01, p. 41-66, 2009.

MAHAR, D.J. Government Policies and Deforestation in Brazil's Amazon Region. Washington, Word Bank Publication, 1989.

MMA (Ministério do Meio Ambiente, dos Recursos Hídricos e da Amazônia Legal) e Banco Mundial. Plano de Ação para a Preservação e Controle do Desmatamento na Amazônia Legal (Brasília: MMA, 2004), 156p.

MMA (Ministério do Meio Ambiente, dos Recursos Hídricos e da Amazônia Legal) e Ministério da Integração Nacional. Plano Amazônia Sustentável - PAS. (Brasília: MMA e MIN, 2004), 87p.

MARGULIS, S. Causas do desmatamento da Amazônia Brasileira. $1^{\text {a }}$ Ed. Brasília: Banco Mundial, 2003. 100p.

MYRDAL, G. Perspectivas de uma Economia Internacional. Rio de Janeiro: Ed. Saga, 1967. p. 23-98 e 295-383. 
NEPSTAD, D; CAPOBIANCO, J.P; BARROS, A.C.; CARVALHO, G.; MOUTINHO, P.; LOPES, U,; LEFEBVRE, P. Avança Brasil: Os custos ambientais para a Amazônia. Belém: Gráfica e Editora Alves, 2000. 24p.

NORTH, D. Instituiciones, cambio institucional y desempeño econômico. Fondo de Cultura Económica. México, 1993.

PRATES, R. C. O desmatamento desigual na Amazônia brasileira: sua evolução, suas causas e consequências sobre o bem-estar. 2008. Tese (doutorado) - Doutorado em Ciências/Economia Aplicada - Universidade de São Paulo, Piracicaba - SP

PREBISCH, R. Dinâmica do Desenvolvimento Latino-Americano. São Paulo: Ed. Fundo de Cultura, 1964. p. 9-82.

SANTOS DE SOUZA, J. R.; ROCHA, E. J. P.; COHEN, J. C. P. "Avaliação dos impactos antropogênicos no ciclo da água na Amazônia." In Aragón, L. E. e Clüsener-Godt, M. (Orgs.) Problemática do uso local e global da água da Amazônia. Belém: UNESCO/NAEA, p. 69-94,2003.

SANTOS, C. A Fronteira do Guaporé. Porto Velho: Edufro, 2007.

SANTOS, M. A Natureza do Espaço: Técnica e Tempo, Razão e Emoção. São Paulo: Editora da Universidade de São Paulo, 2006. 4ª edição

SOUZA, P. J.O.P. Avanço da fronteira agrícola na Amazônia: impactos no balanço de energia e simulação do crescimento e rendimento da soja. Folha Socioambiental (UFRA), v. 01, n.2, nov-dez, 2010.

WALKER, R.; MORAN, E.; ANSELIN, L. Desflorestation an cattle ranching in the Brazilian Amazon: External capital and household processes. World Development, v.28, n.02, p. 683-699, 2000.

Sites acessados

http://www.inpe.br/cra/projetos_pesquisas/terraclass.php.Acesso em: 03 de setembro de 2012. 